\title{
Supplementary Materials for CMOS-compatible Protonic Programmable Resistor based on Phosphosilicate Glass Electrolyte for Analog Deep Learning
}

Authors: Murat Onen ${ }^{1,2}$, Nicolas Emond ${ }^{2,3}, \mathrm{Ju} \mathrm{Li}^{2,3,4,}$, Bilge Yildiz ${ }^{2,3,4,}$, , Jesús A. del Alamo $1,2, *$

\section{Affiliations:}

1 Microsystems Technology Laboratories, Massachusetts Institute of Technology, 77 Massachusetts Avenue, Cambridge, MA 02139, USA

2 MIT-IBM Watson AI Lab, 75 Binney St, Cambridge, MA 02142, USA

3 Department of Materials Science and Engineering, Massachusetts Institute of Technology, 77 Massachusetts Avenue, Cambridge, MA 02139, USA

4 Department of Nuclear Science and Engineering, Massachusetts Institute of Technology, 77 Massachusetts Avenue, Cambridge, MA 02139, USA

*Corresponding Authors: alamo@mit.edu, byildiz@mit.edu, liju@mit.edu

\section{Device Operation}

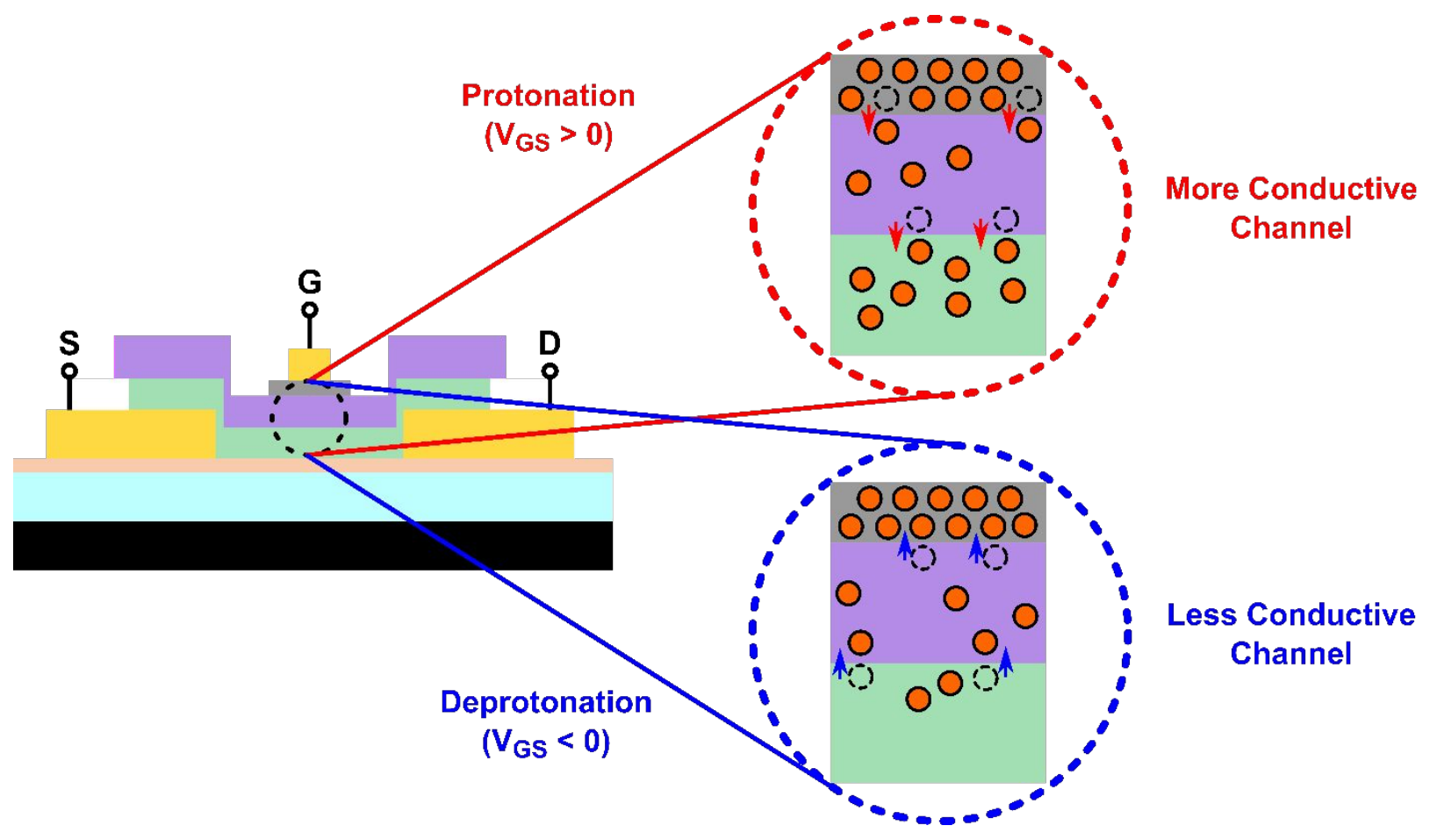


Figure S1. Operational illustration of CMOS-compatible protonic nonvolatile resistors studied in this work.

\section{Fabrication Flow}

- Atomic Layer Deposition (ALD) of $90 \mathrm{~nm} \mathrm{Al} \mathrm{Al}_{2} \mathrm{O}_{3}$ (for proton blocking properties) and $10 \mathrm{~nm} \mathrm{HfO}_{2}$ (to protect $\mathrm{Al}_{2} \mathrm{O}_{3}$ from TMAH and $\mathrm{CF}_{4}$ plasma) on an undoped 4 " $\mathrm{Si}$ wafer for electronic and protonic insulation.

- Spin-coating of Polymethylglutarimide (PMGI) at $4 \mathrm{krpm}$ for $60 \mathrm{~s}$ (thickness $\approx 120$ $\mathrm{nm}$ ) and baking at $180^{\circ} \mathrm{C}$ for $90 \mathrm{~s}$. Spin-coating of Microposit S1813 positive tone photoresist at $4 \mathrm{krpm}$ for $60 \mathrm{~s}$ (thickness $\approx 1.8 \mu \mathrm{m}$ ) and baking at $100^{\circ} \mathrm{C}$ for $90 \mathrm{~s}$.

- Exposition of the source and drain electrode (M1) layout using a Heidelberg maskless aligner (MLA) 150 with a $405 \mathrm{~nm}$ laser wavelength and at a dose of $80 \mathrm{~mJ} / \mathrm{cm}^{2}$.

- Development of the photoresist in MF CD-26 for $80 \mathrm{~s}$ followed by rinsing in deionized (DI) water for $60 \mathrm{~s}$.

- Deposition of $5 \mathrm{~nm} \mathrm{Cr}$ and $15 \mathrm{~nm}$ Au using an electron-beam evaporator.

- Liftoff by soaking the wafer in N-methyl pyrrolidone (NMP) for 5 hours.

- Removal of excess PMGI by soaking the wafer in MF CD-26 for $30 \mathrm{~s}$.

- Spin-coating of Microposit S1813 positive tone photoresist at $4 \mathrm{krpm}$ for $60 \mathrm{~s}$ (thickness $\approx 1.8 \mu \mathrm{m}$ ) and baking at $100^{\circ} \mathrm{C}$ for $90 \mathrm{~s}$.

- Dicing of the 4 " wafer into $1 \times 1 \mathrm{~cm}^{2}$ samples.

- Cleaning of the samples by sonication in acetone and isopropanol baths for $300 \mathrm{~s}$ each.

- Deposition of $10 \mathrm{~nm} \mathrm{WO}_{3}$ using ALD with Bis(tertbutylimino)bis(dimethylamino)tungsten (VI) (BTBMW) and $\mathrm{O}_{3}$ precursors at $330^{\circ} \mathrm{C}$.

- Plasma-Enhanced Chemical Vapor Deposition (PECVD) of $10 \mathrm{~nm}$ PSG using 1420 sccm $\mathrm{N}_{2} \mathrm{O}, 12 \mathrm{sccm} \mathrm{SiH}_{4}$, and $12 \mathrm{sccm} \mathrm{PH}_{3}\left(2 \%\right.$ in $\left.\mathrm{H}_{2}\right)$ at $100^{\circ} \mathrm{C}$, with a RF plasma power of $60 \mathrm{~W}$ at $380 \mathrm{kHz}$.

- Spin-coating of Microposit S1813 positive tone photoresist at $4 \mathrm{krpm}$ for $60 \mathrm{~s}$ (thickness $\approx 1.8 \mu \mathrm{m}$ ) and baking at $100^{\circ} \mathrm{C}$ for $90 \mathrm{~s}$.

- Exposition of the active layer ( $\mathbf{W O}_{3}$ and PSG channel pattern) layout using a Heidelberg-MLA 150 with a $405 \mathrm{~nm}$ laser wavelength and at a dose of $80 \mathrm{~mJ} / \mathrm{cm}^{2}$.

- Development of the photoresist in MF CD-26 for $60 \mathrm{~s}$ followed by rinsing in DI water for another $60 \mathrm{~s}$.

- Patterning of both PSG and $\mathrm{WO}_{3}$ layers using Reactive Ion Etching (RIE) with a $\mathrm{CF}_{4}$ plasma at $100 \mathrm{~W}$ for $180 \mathrm{~s}$ (partitioned in $60 \mathrm{~s}$ intervals).

- Selective wet-etching (undercut) of the $\mathrm{WO}_{3}$ layer in MF CD-26 for $300 \mathrm{~s}$ at room temperature.

- Stripping of the excess photoresist in N-methyl pyrrolidone (NMP) bath for 12 hours. 
- Spin-coating of PMGI at $4 \mathrm{krpm}$ for $60 \mathrm{~s}$ (thickness $\approx 120 \mathrm{~nm}$ ) and baking at $180^{\circ} \mathrm{C}$ for $90 \mathrm{~s}$. Spin-coating of Microposit S1813 positive tone photoresist at $4 \mathrm{krpm}$ for 60 $\mathrm{s}$ (thickness $\approx 1.8 \boldsymbol{\mu \mathrm { m }}$ ) and baking at $100^{\circ} \mathrm{C}$ for $90 \mathrm{~s}$.

- Exposition of the gate electrode layout (M2) using Heidelberg-MLA 150 with a 405 $\mathrm{nm}$ laser wavelength and at a dose of $80 \mathrm{~mJ} / \mathrm{cm}^{2}$.

- Development of the photoresist in MF CD-26 for $80 \mathrm{~s}$ followed by rinsing in DI water for another $60 \mathrm{~s}$.

- Deposition of $5 \mathrm{~nm}$ Pd using an electron-beam evaporator at a low deposition rate ( $\leq$ $0.5 \AA / s)$.

- Liftoff by soaking the pieces in NMP for 5 hours.

- Removal of the excess PMGI by soaking the pieces in MF CD-26 for $30 \mathrm{~s}$

- Spin-coating of PMGI at $4 \mathrm{krpm}$ for $60 \mathrm{~s}$ (thickness $\approx 120 \mathrm{~nm}$ ) and baking at $180^{\circ} \mathrm{C}$ for $90 \mathrm{~s}$. Spin-coating of Microposit S1813 positive tone photoresist at $4 \mathrm{krpm}$ for 60 $\mathrm{s}$ (thickness $\approx 1.8 \mu \mathrm{m}$ ) and baking at $100^{\circ} \mathrm{C}$ for $90 \mathrm{~s}$.

- Exposition of the pad (M3) layout using Heidelberg-MLA 150 with a $405 \mathrm{~nm}$ laser wavelength and at a dose of $80 \mathrm{~mJ} / \mathrm{cm}^{2}$.

- Development of the photoresist in MF CD-26 for $80 \mathrm{~s}$ followed by rinsing in DI water for $60 \mathrm{~s}$.

- Deposition of $10 \mathrm{~nm} \mathrm{Cr}$ and $150 \mathrm{~nm}$ Au using an electron-beam evaporator.

- Liftoff by soaking the wafer in NMP for 5 hours.

The sheet resistance of the ALD $\mathrm{WO}_{3}$ was $\sim 18.2 \mathrm{k} \Omega / \square$ as deposited, which then slightly decreased to $\sim 13.5 \mathrm{k} \Omega / \square$ during the fabrication process. On the other hand, the PSG layer we used in this work shows good electronic insulation properties. For example, for a device with 5 um width and $50 \mu \mathrm{m}$ length, $3 \mathrm{~V}$ gate voltage yielded a current of $\sim 200 \mathrm{pA}(\sim 15 \mathrm{G} \Omega)$, indicating that the electrolyte layer is much more resistive than the channel layer $\left(\mathrm{R}_{\mathrm{SD}} \sim 1.4 \mathrm{M} \Omega\right)$.

Regarding the yield rate of this process, 130 devices were fabricated on a $1 \times 1 \mathrm{~cm}^{2} \mathrm{chip}$. Out of the 50 devices we measured, 41 functioned successfully and reproducibly over the course of more than 2 months of experimentation.

Since we demonstrate standard Si fabrication compatibility, the fabrication flow can be easily adapted to yield nanoscale devices by simply replacing photolithography steps with electron- 
beam lithography steps.

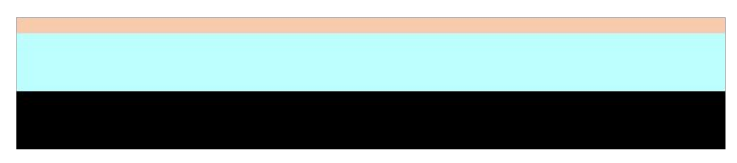

Si (Substrate)

$\mathrm{Al}_{2} \mathrm{O}_{3}$ Deposition (ALD)

$\mathrm{HfO}_{2}$ Deposition (ALD)

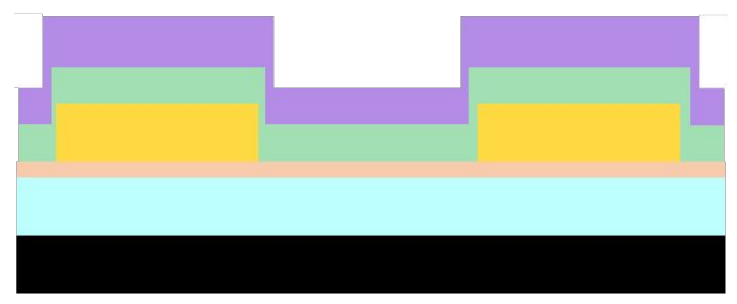

$\mathrm{WO}_{3}$ Deposition (ALD)

PSG Deposition (PECVD)

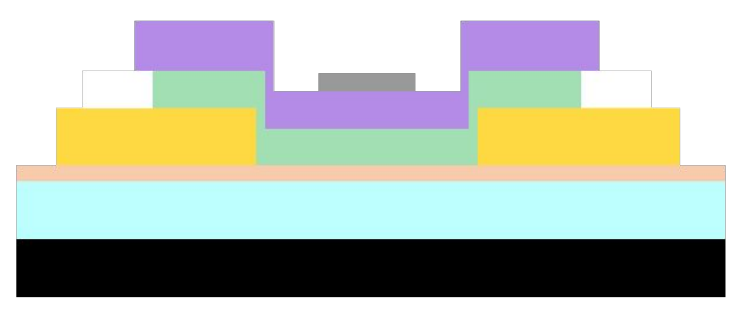

Pd Liftoff (Reservoir)

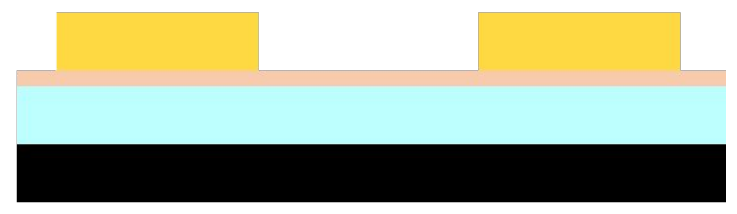

Au/Cr Liftoff (Source-Drain)

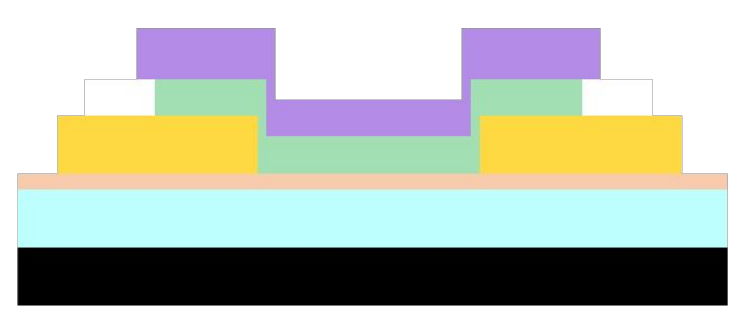

$\mathrm{CF}_{4} \mathrm{RIE}+\mathrm{TMAH}$ Undercut $\left(\mathrm{WO}_{3}\right)$

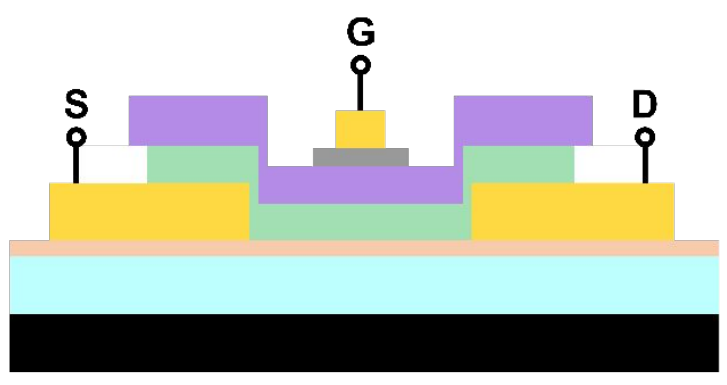

Au/Cr Liftoff (Pads)

Figure S2. Fabrication flow of CMOS-compatible protonic nonvolatile resistors based on PSG electrolyte. 


\section{Methods}

All electrical measurements were performed using a micro-probe station enclosed chamber (MPS-PT) manufactured by NEXTRON, Korea. In experiments performed in forming gas ( $\mathrm{FG}, 3 \% \mathrm{H}_{2}$ in $\mathrm{N}_{2}$ ) all $4 \mathrm{DC}$ probes where first connected to the pads of the device under test ( 1 to Source, 1 to Drain and 2 to Gate terminals). The chamber was then purged by flowing in FG for $60 \mathrm{~s}$ with both gas inlet and outlet open, followed by another $60 \mathrm{~s}$ with outlet shut to create positive pressure inside the chamber.

Three of the probes (1 Source, 1 Drain and $1^{\text {st }}$ Gate) were then connected to the Source Measurement Units (SMUs) of a Keysight B1500 Semiconductor Analyzer, while the fourth probe ( $2^{\text {nd }}$ Gate) was connected to the Pulse Generation Unit (PGU) of the same instrument. The experiment sequence and data acquisition were controlled via an in-house developed MATLAB suite.

\section{Additional Results}

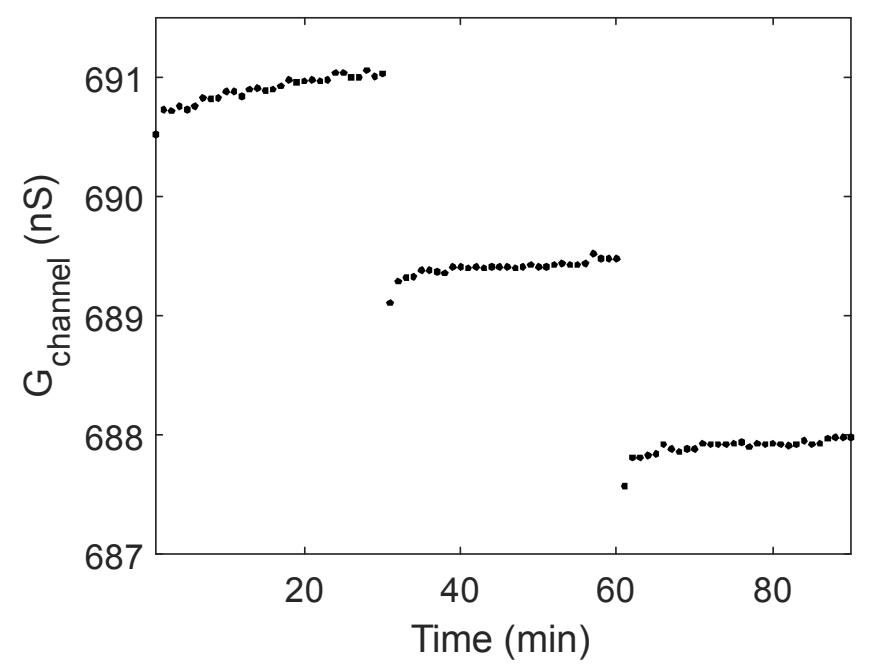

Figure S3. Retention characteristics of the protonic device incrementally programmed by a voltage pulse $\left(V_{\text {pulse }}=-4 V, t_{\text {pulse }}=1 \mathrm{~s}\right)$ at 30 and 60 minutes. Each conductance state is read every minute by sweeping $V_{S D}$ between $\pm 0.1 \mathrm{~V}$ while the gate terminal is floating. Conductance of the device remains distinctly separate from adjacent levels over 30 minutes of readout. 

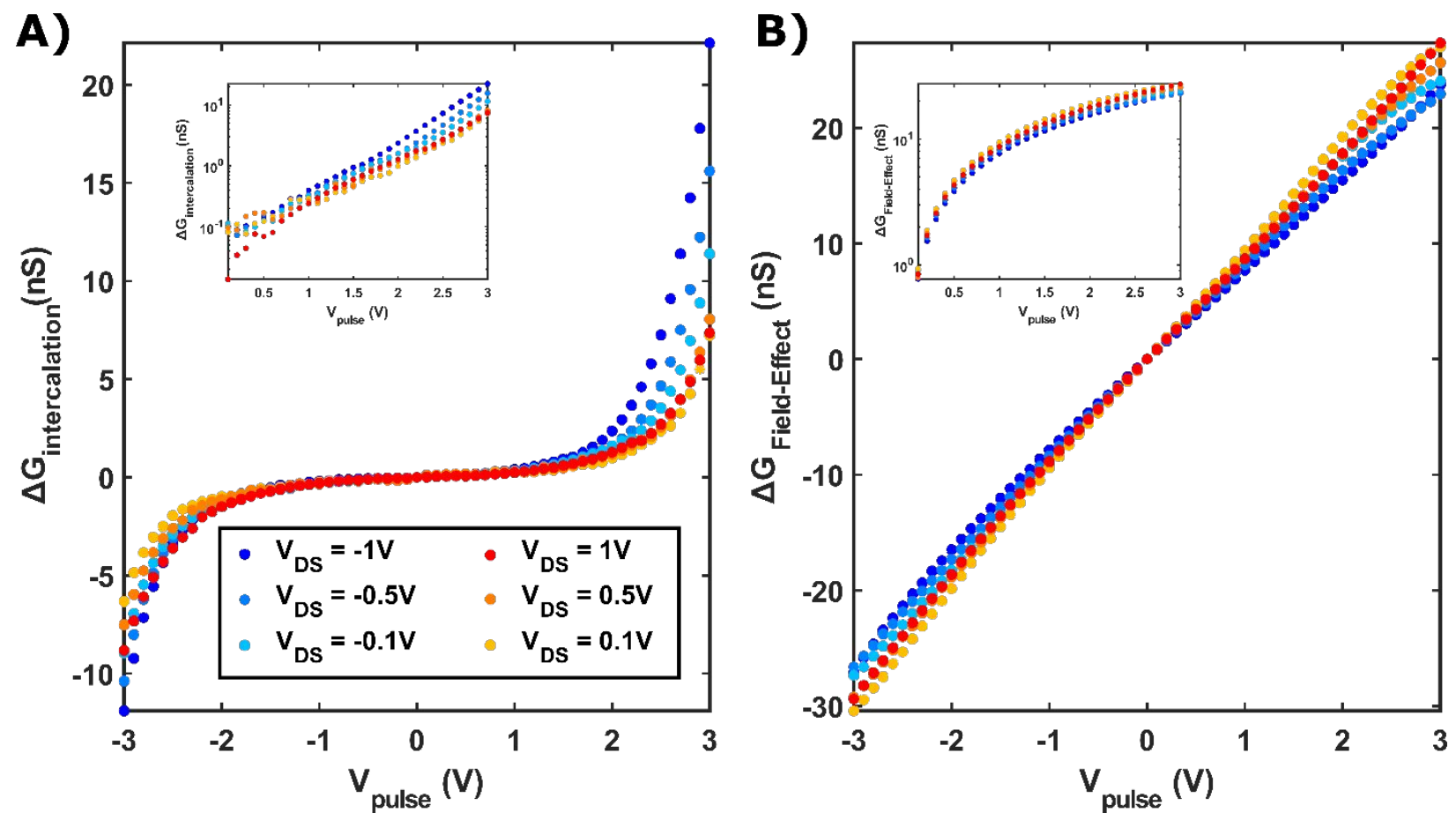

Figure S4. (A) Intercalation and (B) field-effect conductance modulation as a function of the pulse gate voltage for different read drain-source voltage.

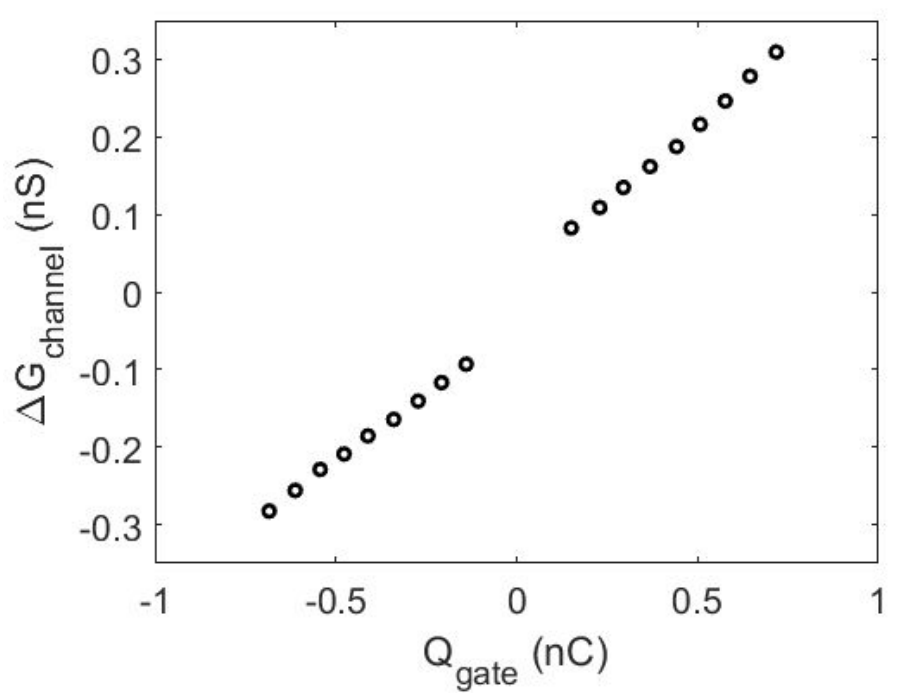

Figure S5. Linear dependence of change in channel conductance $\left(\Delta \mathrm{G}_{\text {channel }}\right)$ as a function of charge injected to / extracted from the gate $\left(\Delta Q_{\text {gate }}\right)$. 

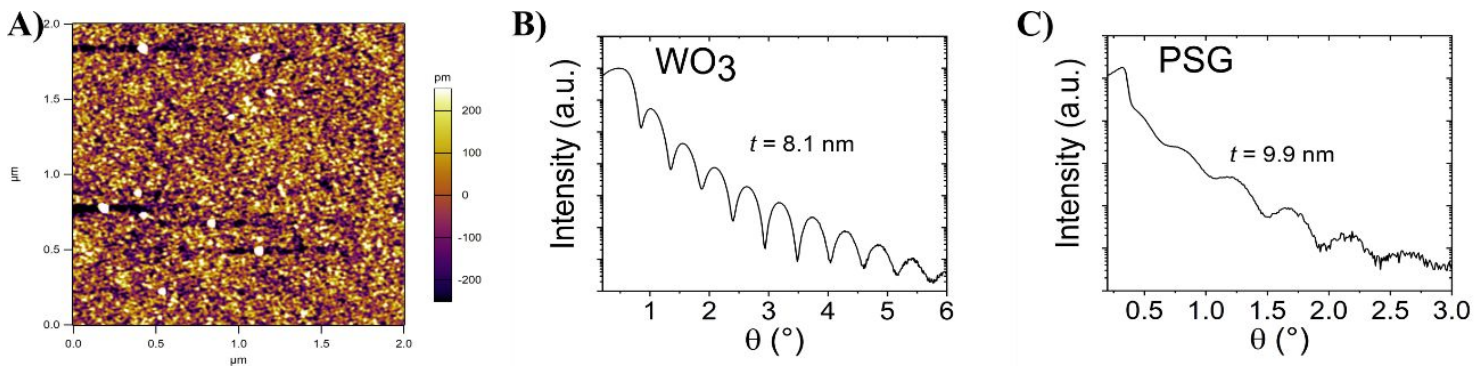

Figure S6. (A) Atomic force microscopy image of the reference $\mathrm{ALD} \mathrm{WO}_{3}$ thin film surface, deposited on a Si surface alongside the patterned sample. X-ray reflectivity (XRR) curve of the reference (B) $\mathrm{ALD} \mathrm{WO}_{3}$ and (C) PSG 12:12 thin films, deposited on a Si surface alongside the patterned samples.

The very smooth surface and low RSM roughness $(\approx 0.2 \mathrm{~nm})$ of the ALD $\mathrm{WO}_{3}$ film as well as the presence of well-defined thickness-interference (Kiessig) fringes in the XRR curves of both $\mathrm{WO}_{3}$ and PSG indicates that the films' surface is smooth and the film-substrate interface well defined. The film thickness $(t)$ can thus be calculated from these XRR curves from the following equation $t=\frac{(m-n) \lambda}{2\left(\sin \theta_{m}-\sin \theta_{n}\right)}$

where $m$ and $n$ are the orders of interference, and $\theta_{m}$ and $\theta_{n}$ are the corresponding diffraction angles, respectively.

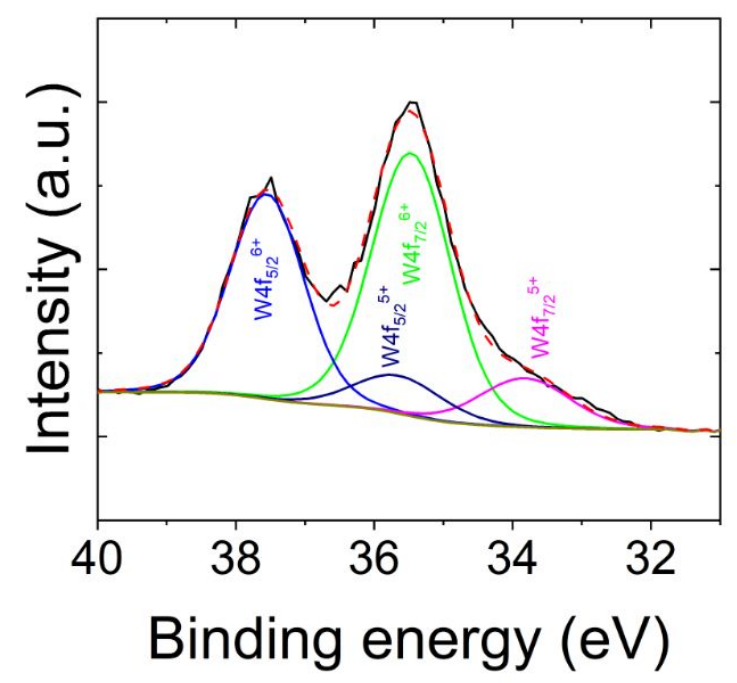

Figure S7. X-ray photoelectron spectra of the $\mathrm{W} 4 f$ peak of a $\mathrm{WO}_{3}$ thin film deposited by ALD. The $\mathrm{W} 4 f_{5 / 2}$ and $\mathrm{W} 4 f_{7 / 2}$ peaks deconvolution between the $\mathrm{W}^{6+}$ and $\mathrm{W}^{5+}$ oxidation states evidences a strong $\mathrm{W}^{5+}$ contribution $\left(\approx 1 \mathrm{~W}^{5+}: 4 \mathrm{~W}^{6+}\right.$ ratio), indicative of the initial reduced (substoichiometric, $\mathrm{WO}_{3-\mathrm{x}}$ ) nature of the film. 


\section{Additional Discussion}

Unlike the P-concentration in PSG, we did not control the amount of $\mathrm{H}$ in $\mathrm{Pd}$. From the pressureconcentration isotherms of the $\mathrm{H} / \mathrm{Pd}$ system given by Lewis (Platinum Metals Rev., 4, 132, 1960 ), the atomic ratio of $\mathrm{H} / \mathrm{Pd}$ at room temperature and ambient pressure is $\sim 0.65$. Since we use premixed 3\% $\mathrm{H}_{2}$ in $\mathrm{N}_{2}$, we have only measured devices with this $\mathrm{H} / \mathrm{Pd}$ ratio and assumed that the amount of $\mathrm{H}$ shuffled in/out of the $\mathrm{WO}_{3}$ channel is much less than the amount of $\mathrm{H}$ stored in the reservoir. There are two reasons behind running the experiments under forming gas environment. (1) Under storage conditions $\left(\mathrm{N}_{2}\right)$ prior to experimentation, $\mathrm{Pd}$ has no $\mathrm{H}$ within. The hydrogenation occurs when the device is enclosed in a forming gas ambient. (2) For Pd to retain $\mathrm{H}$, it should not be exposed to $\mathrm{O}_{2}$, which causes hydrogen to oxidize and leave the reservoir material. Once the reservoir is loaded with $\mathrm{H}$, it can alternatively be operated under an inert environment (e.g. $\mathrm{N}_{2}$, Ar, vacuum) as well.

We want to note that in measurements performed on devices with thicker Pd layers $(\sim 80 \mathrm{~nm})$, we observed that the $\mathrm{H}$ uptake caused volume expansion of the Pd layer to the extent of it getting exfoliated. We anticipate that higher $\mathrm{H}_{2}$ concentration could therefore be problematic even for devices with thinner Pd layers. On the other hand, as the number of protons that are exchanged with the channel layer is much less than what is stored in the reservoir, we expect that devices would be operational under lower $\mathrm{H}_{2}$ concentrations as well. 